Abanico Veterinario. Enero-Diciembre 2020; 10:1-12. http://dx.doi.org/10.21929/abavet2020.14

Artículo Original. Recibido: 26/02/2020. Aceptado: 17/06/2020. Publicado: 05/07/2020.

\title{
Inclusión de harina de calamar gigante Dosidicus gigas como fuente de proteína en dietas para gallinas ponedoras
}

\author{
Giant Squid meal (Dosidicus gigas) inclusion, as a source of protein in laying hens' diet
Carranco-Jáuregui María ${ }^{1}$ ID, Fuente-Martínez Benjamín ${ }^{2}{ }^{\star I D}$, Ramírez-Poblano Miriam $^{3}$, Calvo-Carrillo María ${ }^{1 \mathrm{ID}}$, Ávila-González Ernesto ${ }^{2 \mathrm{ID}}$

\begin{abstract}
1Departamento de Nutrición Animal Dr. Fernando Pérez-Gil Romo, Instituto Nacional de Ciencias Médicas y Nutrición Salvador Zubirán. Ciudad de México. México. ${ }^{2}$ Centro de Enseñanza, Investigación y Extensión en Producción Avícola, Facultad de Medicina Veterinaria y Zootecnia, Universidad Nacional Autónoma de México. Ciudad de México. México. ${ }^{3}$ Alumna de la Facultad de Química, Universidad Nacional Autónoma de México. Ciudad de México. México. *Autor responsable y de correspondencia: Fuente-Martínez Benjamín. Manuel M. López S/N, Colonia Santiago Zapotitlán, Alcaldía Tláhuac, 13209, Ciudad de México. México.rexprimero@hotmail.com, benjaminfuente@yahoo.com.mx, concepcion_calvo1@hotmail.com, avilaernesto@yahoo.com.
\end{abstract}

\section{RESUMEN}

El calamar gigante Dosidicus gigas presenta un potencial para elaborar productos para consumo humano y alimentos balanceados por su alto contenido de proteína. El objetivo de este trabajo fue incluir 10 y $20 \%$ de harina de calamar gigante (HCG) como fuente de proteína en dietas para gallinas ponedoras. Ciento treinta y cinco gallinas Bovans White se distribuyeron en testigo (T), $10 \%$ (T1) y $20 \%$ (T2) en ensayo de 6 semanas. Se midieron variables productivas, calidad física del huevo, proteína cruda, perfil de aminoácidos y evaluación sensorial (sabor). Proteína cruda en HCG (77.76 \%), aminoácidos (g aa/100 de proteína): metionina+cisteína (3.76), lisina (10.16), isoleusina (4.26), leucina (6.56), fenilalanina (4.56) y triptófano (2.0). Variables productivas $(\mathrm{P}<0.05)$ en postura $(\%)$; peso del huevo $(\mathrm{g})$; conversión alimentaria $(\mathrm{kg}: \mathrm{kg})$ y masa de huevo (ave/día/g), y sin diferencia ( $\mathrm{P}>0.05$ ) consumo (ave/día/g). Calidad física del huevo con diferencias $(\mathrm{P}<0.05)$ en peso de huevo $(\mathrm{g})$; altura de albúmina $(\mathrm{mm})$ y unidades Haugh $(\mathrm{UH})$. En huevo proteína cruda y aminoácidos diferencias $(P<0.05)$. Evaluación sensorial $(P>0.05)$, calificando los 3 tratamientos en 4 "gusta". Se concluye que la harina de calamar gigante puede ser una alternativa como fuente de proteína para la alimentación de gallinas de postura no mayor al $10 \%$.

Palabras clave: Harina de calamar gigante, composición química, gallinas ponedoras y huevo.

\begin{abstract}
The giant squid Dosidicus gigas has a great potential to elaborate human consumption products and balanced food due to its high protein content. The objective of this work was to include 10 and $20 \%$ of giant squid meal (GSM) as a protein source in diets for laying hens. One hundred thirty-five Bovans White hens were distributed as follows: control (T), $10 \%$ (T1), and $20 \%$ (T2), in a 6-week trial. The Productive variables measured were the physical quality of the egg, crude protein, amino acid profile, and sensory evaluation (taste), Raw GSM protein (77.76 \%), amino acids (g aa/100 protein): methionine + cysteine (3.76), lysine (10.16), isoleucine (4.26), leucine (6.56), phenylalanine (4.56) and tryptophan (2.0). The Productive variables measured were $(P<0.05)$ in posture $(\%)$; egg weight $(\mathrm{g})$; food conversion $(\mathrm{kg}: \mathrm{kg})$ and egg mass (bird/day/g), and without difference $(P>0.05)$ consumption (bird/day/g); Physical quality of the egg with differences $(P<0.05)$ in egg weight $(\mathrm{g})$, albumin height $(\mathrm{mm})$ and Haugh units $(\mathrm{UH})$. In egg raw protein and amino acid differences $(P<0.05)$, Sensory evaluation $(P>0.05)$, rating the 3 treatments in 4 "likes". According to the results, it is concluded that giant squid flour not exceeding $10 \%$ can be an alternative as a source of protein for feeding posture hens.
\end{abstract}

Keywords: Giant squid meal, chemical composition, laying hens, egg. 


\section{INTRODUCCIÓN}

México es uno de los principales países a nivel mundial en la pesquería del calamar gigante (Dosidicus gigas D'Orbigny 1835) (Montaño et al., 2015). Es una especie oceánica y migratoria del Océano Pacífico Oriental, se distribuye desde Monterey, California, EUA hasta el norte de Chile. De las especies de calamar, el Dosidicus gigas se explota en forma comercial en México, su captura se registra de manera oficial en el Golfo de California y se descarga en los puertos de Mazatlán, Sinaloa; Santa Rosalía, Baja California Sur y Guaymas, Sonora (Luna et al., 2006).

La captura del calamar gigante en los últimos años ha sido abundante e importante, como recurso dentro del sistema productivo pesquero en México; se reportó para el año 2014 la captura de 40,878.02 kg en Guaymas, Sonora (CONAPESCA, 2017). En general se aprovecha el $75 \%$ del calamar sin vísceras, y al ser un alimento de origen marino su valor nutrimental se considera como bueno; destaca el contenido de proteínas (53\%) de fácil digestión (digestibilidad $=94 \%$ ), carbohidratos no asimilables, vitaminas $A, D$ y complejo B, bajo contenido graso y calórico (Martínez-Vega et al., 2000; Luna et al., 2006; Toyes, 2016).

Existe información sobre la ecología, biología, reproducción y distribución del calamar gigante (Dosidicus gigas); así como de la composición química del calamar entero fresco con una humedad de $82.23 \%$, proteína cruda $15.32 \%$, cenizas $1.31 \%$ y grasa $0.87 \%$; en harina se reporta un contenido de proteína cruda $77.76 \%$, cenizas $8.54 \%$ y grasa $6.33 \%$ (Abugoch et al., 1999; Alegre et al., 2014; Calvo et al., 2016).

Por otro lado, la actividad avícola contribuye de manera importante en el sistema de producción de alimentos en el mundo, por lo que se hace necesario una búsqueda para mejorar día a día cada uno de los aspectos involucrados en el proceso de producción. Adquirir el alimento adecuado para obtener resultados óptimos en la avicultura, es un aspecto importante donde el alimento representa el porcentaje más alto dentro de la inversión que se realiza en el ciclo de producción; siendo la proteína el ingrediente de mayor costo en la elaboración de alimentos balanceados. Por lo que las investigaciones en el área avícola se enfocan a la posibilidad de modificar la composición química de sus productos; por ejemplo, reducir el nivel de colesterol y grasa saturada y enriquecerlos con ácidos grasos insaturados, vitaminas, minerales, pigmentos antioxidantes y proteínas; tanto en carne de pollo como en huevo (Morales et al., 2013; Martínez et al., 2016).

El uso de la harina de calamar gigante (HCG) en bioensayos aplicados a gallinas ponedoras, permitirá conocer el nivel óptimo de inclusión en la dieta para aprovechar este recurso proteínico en la industria avícola. La HCG se ha utilizado como alimento en granjas camaroneras, pero no hay literatura científica que reporte su uso como alimento para aves, como se ha realizado con otros productos de origen marino como aceites y harinas de pescados, crustáceos y algas marinas; como fuentes de proteínas, ácidos grasos $n-3$ y $n-6$ y pigmentos. 
El objetivo de esta investigación fue determinar el efecto de la inclusión de harina de calamar gigante, como fuente de proteína en dietas para gallinas ponedoras, y su efecto sobre las variables productivas y calidad del huevo.

\section{MATERIAL Y MÉTODOS}

\section{Obtención, recepción y almacenamiento de la harina de calamar gigante (HCG)}

La HCG (manto, tentáculos, vísceras, pluma y boca) fue proporcionada por una planta procesadora de productos marinos en Guaymas, Sonora, México, se transportó al Departamento de Nutrición Animal Dr. Fernando Pérez-Gil Romo del Instituto Nacional de Ciencias Médicas y Nutrición Salvador Zubirán, y se mantuvieron en congelación (-20 $\left.{ }^{\circ} \mathrm{C}\right)$ hasta su análisis y uso.

\section{Análisis químico de la harina de calamar gigante (HCG)}

Se analizó por los métodos estandarizados descritos por AOAC (2005) (6 repeticiones): humedad por estufa de secado (método 934.01), cenizas por calcinación (método 942.05), proteína cruda por Kjeldahl ( $\mathrm{N} \times$ 6.25) (método 976.05), extracto etéreo por Soxhlet (método 2003.06) y extracto libre de nitrógeno y minerales por espectrofotometría de absorción atómica. Energía bruta utilizando Bomba Calorimétrica (Parr Instrument Company, Inc., Moline Illinois). Perfil de aminoácidos por HPLC (Método Waters, 1993). Estándares de aminoácidos hidrolizados, Marca Pierce, Catálogo $\mathrm{NCl} 0180$.

La muestra se hidrolizó con fenol y $\mathrm{HCl} 6 \mathrm{~N}$, para posteriormente derivatizarla con un buffer de fosfatos y 6-aminoquilonil-N-hidroxisuccimonolil carbamato (reactivo derivatizante AccQ-tag fluor), convirtiendo los aminoácidos primarios y secundarios en derivados estables de ureas que fluorescen fuertemente a $395 \mathrm{~nm}$. Los estándares se derivatizan de igual manera que la muestra.

Condiciones HPLC (Waters modelo 2475): se empleó una columna AccQ-Tag de alta eficiencia Nova-Pak C18 de $4 \mu \mathrm{m}$, fase móvil con eluyente A: buffer WATERS AccQ-TAG; eluyente B: acetonitrilo y eluyente C: Agua MILLI-Q Grado HPLC, tiempo de corrida 60 min., detector fluorescencia Waters $470 \mathrm{~nm}$, temperatura de columna $37{ }^{\circ} \mathrm{C}$ y volumen de inyección $5 \mu \mathrm{L}$, y se continua con el procedimiento analítico descrito en el Manual Operativo de Waters para esta columna (Waters 1993).

\section{Elaboración de dietas y comportamiento de las aves}

El estudio se llevó a cabo en el Centro de Enseñanza, Investigación y Extensión en Producción Avícola (CEIEPAv) de la Facultad de Medicina Veterinaria y Zootecnia de la Universidad Nacional Autónoma de México, Ciudad de México, con una altura de 2,250 $\mathrm{m}$ sobre nivel del mar, clima templado-húmedo, temperatura promedio anual de $16{ }^{\circ} \mathrm{C}$ y precipitación pluvial media anual de $747 \mathrm{~mm}$ (CONAGUA, 2019). El procedimiento que se siguió en el manejo de las aves cumplió con la NOM-062-ZOO-1999, especificaciones técnicas para la producción, cuidado y uso de los animales de laboratorio. 
Tabla 1. Dietas experimentales suplementadas con harina de calamar gigante Dosidicus gigas

\begin{tabular}{|c|c|c|c|}
\hline Ingrediente & Testigo (T) & $\mathrm{T}+10 \% \mathrm{HCG}$ & $\mathrm{T}+20 \% \mathrm{HCG}$ \\
\hline Sorgo & 564.823 & 621.553 & 652.180 \\
\hline Pasta de soya & 269.096 & 197.115 & 149.015 \\
\hline Carbonato de calcio & 99.593 & 99.902 & 100.164 \\
\hline Aceite vegetal & 38.212 & 28.320 & 21.560 \\
\hline Harina Calamar Gigante (HCG) & 0.000 & 26.910 & 53.820 \\
\hline Ortofosfato 1820 & 16.490 & 14.768 & 12.940 \\
\hline Sal $(\mathrm{NaCl})$ & 4.649 & 4.671 & 4.688 \\
\hline DL-Metionina $99 \%$ & 1.768 & 1.566 & 1.134 \\
\hline Premezcla de vitaminas ${ }^{1}$ & 1.000 & 1.000 & 1.000 \\
\hline Premezcla de minerales ${ }^{2}$ & 0.500 & 0.500 & 0.500 \\
\hline Toxisorb ${ }^{3}$ & 1.000 & 1.000 & 1.000 \\
\hline Avelut polvo ${ }^{4}$ & 1.000 & 1.000 & 1.000 \\
\hline L-Lisina $\mathrm{HCl} 78.8 \%$ & 0.870 & 0.693 & 0.000 \\
\hline Cloruro de colina $60 \%$ & 0.500 & 0.500 & 0.500 \\
\hline Pigmento rojo vegetal $^{5}$ & 0.200 & 0.200 & 0.200 \\
\hline Antioxidante 6 & 0.150 & 0.150 & 0.150 \\
\hline Furafeed $^{7}$ & 0.150 & 0.150 & 0.150 \\
\hline Total & 1000.0 & 1000.0 & 1000.0 \\
\hline Precio (Moneda Nacional) & 120.59 & 109.51 & 99.52 \\
\hline & \multicolumn{3}{|c|}{ Análisis de nutrientes } \\
\hline Energía metabolizable, $\mathrm{kcal} / \mathrm{kg}$ & 2.871 & 2.850 & 2.850 \\
\hline Proteína cruda, \% & 18.334 & 17.274 & 17.169 \\
\hline Metionina + cistina total, $\%$ & 0.747 & 0.743 & 0.741 \\
\hline Lisina total, \% & 0.963 & 0.961 & 0.984 \\
\hline Treonina total, \% & 0.686 & 0.702 & 0.756 \\
\hline Triptófano total, \% & 0.228 & 0.186 & 0.157 \\
\hline Calcio total, \% & 4.001 & 4.001 & 4.001 \\
\hline Fósforo disponible, \% & 0.440 & 0.440 & 0.440 \\
\hline Sodio, \% & 0.190 & 0.190 & 0.190 \\
\hline
\end{tabular}

${ }^{1}$ Contenido de vitaminas por kg: A; 4.0 MUI: $\mathrm{D}_{3} ; 666,666.7 \mathrm{Ul}$ : RovomixHyD; $5 \mathrm{~kg}$ : $\mathrm{K}_{3} ; 1.67 \mathrm{~g}: \mathrm{B}_{1} ; 0.83 \mathrm{~g}$ : $\mathrm{B}_{2} ; 2.33 \mathrm{~g}: \mathrm{B}_{6} ; 1.17 \mathrm{~g}: \mathrm{B}_{12} ; 6,666.67 \mathrm{mg}$ : Niacina; $10 \mathrm{~g}$ : Ácido D-Pantoténico; $3.33 \mathrm{~g}:$ Ácido fólico; $0.33 \mathrm{~g}:$ Biotin; 33.33 mg: Colina; 100 g. ${ }^{2}$ Contenido de minerales por kg: Hierro; 20 g: Zinc; 26.67 g: Manganeso; $36.67 \mathrm{~g}$ : Cobre; $5 \mathrm{~g}$ : lodo; $0.33 \mathrm{~g}$ : Selenio; $0.1 \mathrm{~g} .{ }^{3}$ Secuestrante de micotoxinas. ${ }^{4}$ Fuente de xantofilas naturales amarillas. ${ }^{5}$ Avired: $5 \mathrm{~g} / \mathrm{kg}$ (mínimo) de xantofilas de frutos de Capsicum spp. ${ }^{6} \mathrm{BHA} ; 1.2 \%$ : BHT; $9.0 \%$ : Etoxiquin; $4.8 \%$ : Agentes quelantes; $10.0 \%$. ${ }^{7}$ Antimicótico.

Se utilizaron 135 gallinas Bovans White de primer ciclo, 18 semanas de edad, alojadas en jaulas en batería con 3 gallinas cada una; fueron distribuidas con un diseño completamente al azar en 3 tratamientos con 5 repeticiones con 9 aves cada uno: dieta testigo, $10 \%$ y $20 \%$ de proteína proveniente de HCG. Se utilizó el programa computacional Allix2. Ver 5.37.1 para formular las dietas experimentales suplementadas con HCG. El procedimiento empleado consiste en incluir los datos provenientes del análisis químico proximal de los ingredientes; el cálculo se hizo con base al aporte proteínico, donde la proteína de la HCG sustituyó parcialmente a la de la pasta de soya, 
que cumplió con las necesidades nutricionales de la estirpe de acuerdo con la fase de producción (tabla 1).

\section{Cuantificación de proteína cruda y perfil de aminoácidos en el huevo}

Al final de la evaluación de la calidad física del huevo, de estos mismos, se tomaron al azar 5 de cada repetición y se mezclaron con una batidora de mano, y se les realizó la cuantificación de proteína cruda por el método de Kjeldahl (AOAC, 2005). La cuantificación del perfil de aminoácidos se llevó a cabo por HPLC, mediante el método AccQ-TAG Waters 1993 (Manual No. WATO52874, Waters, 1993).

\section{Evaluación sensorial}

Se muestrearon 10 huevos de cada tratamiento (2 por repetición), se cocinaron en forma de huevo revuelto sin aceite y sin sal. Se llevó a cabo una prueba de nivel de agrado para el sabor, y se estableció una escala de 5 puntos ( 1 = disgusta mucho; 2 = disgusta; 3 = ni gusta ni disgusta; 4 = gusta y 5 = gusta mucho). Participaron 30 jueces no entrenados, pero sí consumidores habituales de huevo (Anzaldúa, 2014).

\section{Análisis estadístico}

Para todas las variables estudiadas se llevó a cabo un análisis de varianza (ANDEVA) con un $95 \%$ de confianza, y la diferencia entre medias por la prueba de Tukey, a través del paquete estadístico de Statistical Analysis System (SAS Inst. Inc., 2003). Los resultados de la evaluación sensorial se analizaron mediante la prueba no paramétrica de Friedman $(P<0.05)$ (Anzaldúa, 2014).

\section{RESULTADOS Y DISCUSIÓN}

\section{Análisis químicos a la HCG y a las dietas}

En la tabla 2, se presenta la composición química de la harina de calamar gigante (HCG), en donde se destaca el valor de proteína cruda (77.76 \% BH y de $82.82 \%$ BS). Toyes (2016) reporta un contenido de proteína cruda en harina de vísceras de calamar de la misma especie de $53 \%$, observándose una diferencia del $28 \%$ menor que en HCG. Sin embargo, Ezquerra et al. (2007) reportaron que del total de la proteína cruda de varias especies de calamares, los elementos no nitrogenados (óxido de trimetilamina y otras aminas, aminoácidos libres y octopina, arginina, glicina, betaína, alanina y nucleótidos), constituyen el $37 \%$; aunque estos autores no especifican si este valor corresponde a calamar entero o sólo partes comestibles, y si es fresco o en harina; sin embargo, Maza et al. (2003), mencionan en su estudio que el contenido de nitrógeno no proteico en manto fresco de calamar gigante es de $39.5 \%$. Por otro lado, en la HCG las cenizas (8.54 \%), están constituidas por principalmente por hierro y sodio $(0.19$ y $0.16 \mathrm{mg} / 100 \mathrm{~g})$, respectivamente. Como parte del proceso para la obtención de la HCG, se realiza un prensado que genera un fluido formado por agua y aceite, por lo que el contenido de 
grasa en la harina fue de $6.33 \%$; por ese motivo el aporte energético es menor 4.03 $\mathrm{Kcal} / \mathrm{g}$, siendo similar a lo publicado en harina de calamar Illex illecebrosus $(4.13 \mathrm{Kcal} / \mathrm{g})$ (Calvo et al., 2016).

Cabe señalar que la diferencia reportada de los resultados de este estudio con referencia a otros autores podría deberse a la especie de calamar, temporada de captura, partes del calamar analizados, manejo y preparación de las muestras para análisis (fresco o en harina).

Tabla 2. Composición química, perfil de aminoácidos y minerales en harina de calamar gigante (HCG) Dosidicus gigas

\begin{tabular}{|c|c|c|}
\hline & HCG/base húmeda & HCG/base seca \\
\hline \multicolumn{3}{|l|}{ Análisis proximal $(\mathrm{g} / 100 \mathrm{~g})^{1}$} \\
\hline Humedad & $3.46 \pm 0.002$ & ---- \\
\hline Proteína cruda & $77.76 \pm 0.04$ & 80.54 \\
\hline Extracto etéreo & $6.33 \pm 0.007$ & 6.55 \\
\hline Cenizas & $8.54 \pm 0.002$ & 8.84 \\
\hline Extracto libre de nitrógeno ${ }^{2}$ & 3.91 & 4.07 \\
\hline Energía Bruta (Kcal/g) & $4.03 \pm 0.02$ & 4.17 \\
\hline Aminoácidos & (g aa/100 g de proteína) & \\
\hline Metionina* $^{*}$ & $1.64 \pm 0.01$ & 1.69 \\
\hline Cisteína & $2.12 \pm 0.03$ & 2.19 \\
\hline Metionina + Cistina & 3.76 & 3.89 \\
\hline Lisina* $^{*}$ & $10.16 \pm 0.03$ & 10.52 \\
\hline Treonina* & $3.86 \pm 0.02$ & 3.99 \\
\hline Ácido aspártico & $9.53 \pm 0.01$ & 9.87 \\
\hline Ácido glutámico & $14.53 \pm 0.02$ & 15.05 \\
\hline Prolina & $5.16 \pm 0.03$ & 5.34 \\
\hline Glicina & $7.57 \pm 0.03$ & 7.84 \\
\hline Alanina & $6.79 \pm 0.03$ & 7.03 \\
\hline Valina* & $5.40 \pm 0.03$ & 5.59 \\
\hline Isoleucina* & $4.26 \pm 0.01$ & 4.41 \\
\hline Leucina* & $6.56 \pm 0.02$ & 6.79 \\
\hline Serina & $3.42 \pm 0.02$ & 3.54 \\
\hline Fenilalanina* & $4.56 \pm 0.02$ & 4.72 \\
\hline Arginina & $3.86 \pm 0.02$ & 3.99 \\
\hline Histidina* & $6.89 \pm 0.03$ & 7.13 \\
\hline Triptófano* & $2.0 \pm 0.03$ & 2.07 \\
\hline Minerales & $(\mathrm{mg} / 100 \mathrm{~g})$ & \\
\hline Calcio & $0.15 \pm 0.001$ & 0.15 \\
\hline Sodio & $0.16 \pm 0.005$ & 0.16 \\
\hline Potasio & $0.14 \pm 0.002$ & 0.14 \\
\hline Magnesio & $0.08 \pm 0.005$ & 0.08 \\
\hline Hierro & $0.19 \pm 0.009$ & 0.09 \\
\hline
\end{tabular}

${ }^{1} \mathrm{n}=12 .{ }^{2}$ Por diferencia; *Aminoácidos esenciales 
La calidad de la proteína va de acuerdo con su perfil de aminoácidos esenciales, vinculada con la eficiencia en la conversión proteínica (ECP). En esta HCG se encontró que los valores de lisina, histidina, aminoácidos azufrados y aromáticos fueron similares a los aminoácidos de la leche y el huevo, a excepción de lisina e histidina, presente en mayor cantidad en leche y de valina e isoleucina mayor en huevo (Calvo et al., 2016).

\section{Variables productivas y calidad física del huevo}

En la tabla 3, se observa que hubo diferencias significativas $(P<0.05)$ entre el testigo, $10 \%$ y $20 \%$ de HCG en el \% de postura (91.42, 94.23 y 89.33), peso del huevo (53.61, 52.82 y $52.35 \mathrm{~g})$, conversión alimenticia $(1.96,1.95$ y $2.05 \mathrm{~kg} / \mathrm{kg})$ y masa de huevo (49.11, 49.93 y $46.91 \mathrm{ave} / \mathrm{dí} a / \mathrm{g})$ y sin diferencia $(\mathrm{P}>0.05)$, el consumo de alimento (95.49, 96.16 y $94.07 \mathrm{~g}$ ) respectivamente entre las tres dietas. Al finalizar el estudio las gallinas tenían 24 semanas de edad, y de acuerdo con los datos publicados en la Guía de Manejo de Bovans White (ISA, 2009) el peso de huevo $54.6 \mathrm{~g}$, masa de huevo $49.4 \mathrm{~g}$, consumo de alimento g/día 100 y conversión alimenticia $2.02 \mathrm{~kg} / \mathrm{kg}$; por lo que ambos grupos de datos fueron similares.

Los resultados reportados en este estudio concuerdan con la Guía de Manejo de Bovans White (ISA, 2009), que menciona que las aves entre 30-35 semanas de edad llegan a un buen desarrollo de producción, en donde reportan peso del huevo 60-61 g, masa de huevo de $25.5 \mathrm{~g}$, consumo de alimento $106 \mathrm{~g} /$ día y conversión alimentaria de $2.08 \mathrm{~kg} / \mathrm{kg}$. En cuanto a la calidad física del huevo la Norma Mexicana (NMX-FF-127-SCFI-2016), menciona 5 categorías para huevo fresco determinadas por peso y tamaño (Extra grande $\geq 64$, Grande $60-64$, Mediano 55 - 60, Chico 50 - 55 y Canica $\geq 50$ ). En este estudio, el peso del huevo fue menor con $20 \%$ de HCG $(52.35 \mathrm{~g})$ con respecto al testigo $(53.61 \mathrm{~g})$, por lo que están dentro de la clasificación de chico, justificado este resultado por la edad de las gallinas.

Para esta misma norma mexicana, existe otra clasificación para huevo fresco para plato: extra, categoría I, categoría II y fuera de clasificación, y se refiere principalmente a la apariencia del cascarón (normal, íntegro y limpio); cámara de aire (normal y no exceder los $3.2 \mathrm{~mm}$ ), clara o albúmina y Unidades Haugh (viscosa, limpia y firme), y yema (redonda, al centro, con disco germinal visible y color entre 9 y 13 en la escala del abanico colorimétrico Roche). De acuerdo a esta clasificación la calidad física del huevo estudiado recae en extra, ya que, aunque hubo diferencias significativas en $\mathrm{UH}$ (98.11 para $10 \%$ y 95.86 para $20 \%$ de HCG y testigo de $97.20 \mathrm{UH}$ ) y altura de albúmina (9.42 mm y 8.90 $\mathrm{mm}$ para 10 y $20 \%$ de HCG respectivamente y $9.27 \mathrm{~mm}$ para testigo), están dentro de esta norma. Estas variables indican la frescura del huevo, en donde la albúmina debe estar viscosa (coloidal), la que rodea a la yema, y para distinguir 3 capas (dos densas y 1 acuosa) que conforme pasa el tiempo de postura se pierde $\mathrm{CO}_{2}$ e incrementa el pH de 7.6 hasta 9.7; así como pérdida de humedad en forma de vapor de agua que va a desnaturalizar a las proteínas, y esto hará que la albúmina pierda su estructura, 
haciéndola más líquida y esto lleva a un menor valor de altura de albúmina y UH, así como la capacidad de mantener a la yema en el centro; modificación que se presenta cuando el huevo lleva varios días de puesta. Posiblemente el pequeño incremento de proteína en la dieta al 10 \% de HCG se vio reflejado en las características físicas de la albúmina.

Tabla 3. Promedio de las variables productivas en gallinas Bovans Blanca y calidad física del huevo con diferentes porcentajes de inclusión de harina de calamar gigante (HCG) Dosidicus gigas

\begin{tabular}{|c|c|c|c|}
\hline & \multicolumn{3}{|c|}{ Variables Productivas } \\
\hline & Testigo & $10 \% \mathrm{HCG}$ & $20 \% \mathrm{HCG}$ \\
\hline Postura (\%) & $91.42 \pm 5.08^{b}$ & $94.23 \pm 6.31^{a}$ & $89.33 \pm 10.37^{b}$ \\
\hline Peso de Huevo (g) & $53.61 \pm 2.62^{\mathrm{a}}$ & $52.86 \pm 2.36^{b}$ & $52.35 \pm 2.56^{b}$ \\
\hline Consumo, ave/día (g) & $95.49 \pm 8.24$ & $96.16 \pm 8.80$ & $94.07 \pm 8.37$ \\
\hline Conversión Alimentaria (kg/kg) & $1.96 \pm 0.27^{b}$ & $1.95 \pm 0.28^{b}$ & $2.05 \pm 0.35^{\mathrm{a}}$ \\
\hline \multirow[t]{2}{*}{ Masa de huevo, ave/día (g) } & $49.11 \pm 4.95^{\mathrm{a}}$ & $49.93 \pm 5.44^{a}$ & $46.91 \pm 7.27^{b}$ \\
\hline & \multicolumn{3}{|c|}{ Calidad física del huevo } \\
\hline Peso de Huevo (g) & $53.55 \pm 3.78^{\mathrm{a}}$ & $52.58 \pm 4.90^{\mathrm{b}}$ & $51.83 \pm 3.91^{b}$ \\
\hline Altura de albúmina (mm) & $9.27 \pm 0.96^{a}$ & $9.42 \pm 1.11^{\mathrm{a}}$ & $8.90 \pm 1.05^{b}$ \\
\hline Unidades Haugh (UH) & $97.20 \pm 4.49^{a}$ & $98.11 \pm 5.43^{\mathrm{a}}$ & $95.86 \pm 4.99^{b}$ \\
\hline $\begin{array}{l}\text { Clasificación del huevo de acuerdo a las } \\
\text { Unidades Haugh en México }{ }^{1}\end{array}$ & México Extra & México Extra & México Extra \\
\hline
\end{tabular}

Variables productivas $n=135$. Calidad física del huevo $n=300$. ${ }^{a, b}$ Diferente letra en la misma fila muestra valores estadísticamente distintos $(P<0.05) .{ }^{1}$ Altura de albumen mayor a $5.5 \mathrm{~mm}$ o en Unidades Haugh mayor a 70 (NMX-FF-079-SCFI, 2004)

\section{Cuantificación de proteína cruda y perfil de aminoácidos en huevo}

En la tabla 4, se observa que entre la proteína cruda del huevo con inclusión de $10 \%$ $(12.58 \%)$ y testigo $(12.34 \%)$ no hubo diferencia estadística $(P>0.05)$, pero con $20 \%$ de HCG $(10.79 \%)$ sí hubo diferencia $(P<0.05)$.

En relación con los aminoácidos reportados, hubo diferencia $(P<0.05)$ entre el testigo y las muestras con 10 y $20 \%$ de HCG. Estudios como el de Naber (1979) que clasificó los componentes químicos del huevo basándose en cambios en la dieta de las gallinas, llegó a la conclusión de que los nutrientes proteínas, aminoácidos, grasa total y 
macrominerales muestran escasa variación al modificar la dieta; no así con los microminerales, vitaminas y ácidos grasos que son más influenciables a los cambios en la dieta, todo en función del nutriente que se estudie. Asimismo, Stadelman y Pratt (1989) evaluaron los factores que modifican la composición del huevo y mencionan que el nivel de proteína en éste aumenta ligeramente al incrementar la proteína y la energía de la dieta, que la cantidad total de albumen dependerá del equilibrio de aminoácidos de la dieta, y que una deficiencia en lisina o metionina reducirá el peso del albumen y disminuirá la concentración de todos los aminoácidos libres.

Tabla 4. Contenido de proteína y perfil de aminoácidos en huevo de gallinas alimentadas con diferentes inclusiones de harina de calamar gigante (HCG) Dosidicus gigas

\begin{tabular}{|c|c|c|c|}
\hline & Testigo & $10 \% \mathrm{HCG}$ & $20 \% \mathrm{HCG}$ \\
\hline Proteína cruda (\%) & $12.34 \pm 0.56^{\mathrm{a}}$ & $12.58 \pm 0.32^{\mathrm{a}}$ & $10.79 \pm 0.67^{b}$ \\
\hline \multicolumn{4}{|c|}{ Perfil de aminoácidos (g aa/100g proteína) } \\
\hline Isoleucina* $^{*}$ & $5.26 \pm 0.05^{a}$ & $5.18 \pm 0.03^{a}$ & $4.92 \pm 0.09^{b}$ \\
\hline Leucina* & $8.46 \pm 0.06^{a}$ & $8.26 \pm 0.06^{b}$ & $8.35 \pm 0.03^{b}$ \\
\hline Lisina* & $7.28 \pm 0.07^{a}$ & $6.93 \pm 0.02^{b}$ & $7.17 \pm 0.05^{a}$ \\
\hline Metionina + Cistina* & $3.91 \pm 0.05^{\mathrm{a}}$ & $3.71 \pm 0.10^{b}$ & $3.55 \pm 0.03^{b}$ \\
\hline Fenilalanina* & $5.79 \pm 0.21^{\mathrm{a}}$ & $5.66 \pm 0.06^{b}$ & $5.60 \pm 0.04^{b}$ \\
\hline Treonina* & $4.87 \pm 0.11^{a}$ & $4.68 \pm 0.07^{a}$ & $4.40 \pm 0.05^{b}$ \\
\hline Valina* & $6.52 \pm 0.07^{a}$ & $6.32 \pm 0.07^{b}$ & $6.11 \pm 0.05^{c}$ \\
\hline Tirosina & $4.40 \pm 0.07^{a}$ & $4.21 \pm 0.09^{b}$ & $4.12 \pm 0.06^{b}$ \\
\hline Arginina & $6.74 \pm 0.03^{a}$ & $6.52 \pm 0.06^{b}$ & $6.45 \pm 0.13^{b}$ \\
\hline
\end{tabular}

\section{Evaluación sensorial}

Los resultados obtenidos de la evaluación de sabor de huevo tuvieron un puntaje de 4 , que corresponde al nivel de "gusta". En los comentarios de esta evaluación no hizo referencia a sabores desagradables (tabla 5).

Finalmente cabe mencionar que la composición química del huevo de este estudio en comparación con el huevo testigo y otros reportes, dependerá de la edad de la gallina, la estirpe y tipo de manejo; sin embargo, el factor más importante será la alimentación. 
Tabla 5. Resultados de la evaluación de sabor de huevo de gallinas alimentadas con diferentes inclusiones de harina de calamar gigante (HCG) Dosidicus gigas

\begin{tabular}{llll}
\hline & Testigo & $10 \%$ HCG & $20 \%$ HCG \\
\hline Sabor & $4.16 \pm 1.02$ & $4.09 \pm 0.86$ & $4.06 \pm 1.01$ \\
\hline $\begin{array}{l}\mathrm{n}=30 . \text { Escala de } 5 \text { puntos } \\
\text { mucho) }\end{array}$ & 1= disgusta mucho; $2=$ disgusta; $3=$ ni gusta ni disgusta; $4=$ gusta y $5=$ gusta \\
\end{tabular}

\section{CONCLUSIÓN}

Los resultados obtenidos en este estudio se pueden concluir que la harina de calamar gigante Dosidicus gigas, puede ser empleada como fuente de proteína en dietas para gallinas ponedoras hasta un $10 \%$ de inclusión, sin afectar las variables productivas, el sabor del huevo y con un ligero aumento en el contenido de la proteína del huevo; por lo que puede ser una alternativa el uso de esta harina en la industria avícola.

\section{LITERATURA CITADA}

ABUGOCH L, Guarda A, Pérez LM, Paredes MP. 1999. Determination of proximal chemical composition of squid (Dosidicus gigas) and development of gel products. Archivos Latinoamericanos de Nutricion. 49(2):156-161. https://europepmc.org/article/med/10488395. PMID: 10488395.

ALEGRE Ana, Frédéric Ménard, Ricardo Tafur, Pepe Espinoza, Juan Argüelles, Víctor Maehara, Oswaldo Flores, Monique Simier, Arnaud Bertrand. 2014. Comprehensive Model of Jumbo Squid Dosidicus gigas Trophic Ecology in the Northern Humboldt Current System. PLoS ONE. 9(1): e85919. https://doi.org/10.1371/journal.pone.0085919.

ANZALDÚA MA. 2014. Evaluación sensorial de los alimentos en la teoría y la práctica. Ed. Acribia S.A. Pp. 214. ISBN: 978-84-200-0767-0. https://www.editorialacribia.com/libro/la-evaluacion-sensorial-de-los-alimentos-en-lateoria-y-la-practica_53649/

AOAC. 2005. Official methods of analysis of AOAC International. 18 ed. Arlington, VA, USA. ISBN 0-935584-77-3. http://www.eoma.aoac.org/

CALVO CMC, Carranco JME, Salinas CA, Carrillo DS. 2016. Composición química de harina de calamar gigante Dosidicus gigas. Archivos Latinoamericanos de Nutrición. 66(1): 74-81. ISSN 0004-0622. www. alanrevista.org.

CONAGUA. 2019. Resúmenes mensuales de temperaturas y lluvia. https://smn.conagua.gob.mx/es/climatologia/temperaturas-y-lluvias/resumenesmensuales-de-temperaturas-y-lluvias. 
CONAPESCA. 2017. Estadísticas pesqueras en México. https://www.gob.mx/conapesca/documentos/estadistica-pesquera-y-acuicola-de-mexico.

EZQUERRA-Brauer JM, Díaz AC, Fenucci JL. 2007. Harina de Calamar. Manual de Ingredientes Proteicos y Aditivos en la Formulación de Alimentos Balanceados para Camarones. (García Galano T, Villarreal-Colmenares H, Fenucci JL. Eds). EUDEM. Argentina. ISBN 978-987-1371-02-0. 2007. 41-55. http://retos-aaa.edu.umh.es/wpcontent/uploads/sites/299/2017/06/CV-Marina-J.-Ezquerra.pdf

ISA. 2009. Bovans White. Guía de manejo Sistemas de producción en jaula. Institut de Sélection Animale BV. The Netherlands-EU. Disponible en: https://www.bovans.com/documents/261/HGL_nutrition_management_guide_L7121 2.pdf.

LUNA RMC, Urciaga GJI, Salinas ZCA, Cisneros MMA, Beltrán MLF. 2006. Diagnóstico del consumo del calamar gigante en México y Sonora. Economía, Sociedad y Territorio. 6(22): 535-560. ISSN: 1405-8421. https://doi.org/10.22136/est002006267

MARTÍNEZ-Vega JA, Cruz-Suárez LE, Ricque-Marie D. 2000. Composición corporal y proceso de secado del calamar gigante Dosidicus gigas. Ciencia y Mar. 4(11):35-38. http://www.umar.mx/revistas/

MARTÍNEZ Aispuro JA, González Alcorta MJ, Miranda Romero LA, Carrillo Domínguez S, Castillo Domínguez RM. 2016. Sustitución de aceite de soya por aceite de atún en la dieta de pollos como alternativa para enriquecer la carne con ácidos grasos omega-3. Interciencia. 41(12):851-856. https://www.redalyc. org/articulo.oa?id=33948806009.

MAZA S, Rosales M, Castro R. 2003. Efecto de un proceso de lixiviación ácida salina sobre la calidad del surimi de Dosidicus gigas "Pota". Boletín de Investigaciones Ins. Tec. Pes. Perú. 5: 81-88. ISSN: 1023-7070. http://repositorio.itp.gob.pe/handle/ITP/103.

MONTAÑO MIE, Hernández GLA, Lomelí MH, Mesías DFJ, Ávila AA. 2015. Caracterización del consumidor de calamar gigante en Baja California Sur, México. Ciencia y Tecnología Agropecuaria. 16(1):41-50. ISSN: 0122-8706.

http://www.scielo.org.co/scielo.php?script=sci_arttext\&pid=S0122-

$87062015000100004 \&$ Ing=en\&tlng=es

MORALES BJE, Gonzáles AMJ, Castillo DRM, Prado ROF, Hernández VX, Menconi A, Téllez G, Marshal HB, Carrillo DS. 2013. Fatty Acid Deposition on Broiler Meat in Chickens Supplemented with Tuna Oil. Food and Nutrition Sciences. 4(9A1):5. ID:36099. https://doi.org/10.4236/fns.2013.49A1003 
NABER EC. 1979. The effect of nutrition on the composition of eggs. Poultry Science. 58: 518-528. ISSN: 0032-5791. https://doi.org/10.3382/ps.0580518

NORMA Mexicana NMX-FF-079-SCFI-2004. Para: Productos avícolas - Huevo fresco de gallina - Especificaciones y Métodos de Prueba (Cancela a la NMX-FF-079-1991). Secretaría de Economía, Ciudad de México, México. Publicada en el Diario Oficial de la Federación del 19 de octubre de 2004.Disponible en: http://dof.gob.mx/nota_detalle_popup.php?codigo=5049464

NORMA Mexicana NMX-FF-127-SCFI-2016. Para: Productos avícolas - Huevo fresco de gallina - Especificaciones y Métodos de Prueba. Secretaría de Economía, Ciudad de México, México. Publicada en el Diario Oficial de la Federación del 24 de octubre de 2016. Disponible en: www.dof.gob.mx.

NORMA Oficial Mexicana NOM-062-ZOO-1999. Especificaciones Técnicas para la Producción, Cuidado y Uso de los Animales de Laboratorio. Publicada en el Diario Oficial de la Federación del 18 de junio de 2001. http://www.ibt.unam.mx/computo/pdfs/bioterio.NOM-062.pdf.

SAS Institute Inc. 2004. SAS/STAT ® 9.1 User's Guide. Cary, NC: SAS Institute Inc. ISBN: 1-59047-243-8. https://www.sas.com/es_mx/home.html

STADELMAN WJ, Pratt DE. 1989. Factors influencing composition of the hen's egg. World's. Poultry Science Journal. 45(3): 247-266. https://agris.fao.org/agrissearch/search.do? recordID=GB9103232

TOYES VE. 2016. Aprovechamiento de subproductos marinos para la alimentación de camarón de cultivo y gallinas ponedoras. Tesis Doctoral. México, Centro de Investigaciones Biológicas del Noreste, Baja California, México. http://cibnor.repositorioinstitucional.mx/jspui/handle/1001/215.

WATERS. Water AccQ-Tag Chemistry Package. 1993. Manual Number WAT052874. Millipore Corporation, Milford, MA, USA. www.waters.com. 